\title{
Global Surgery Education and Training Programmes-a Scoping Review and Taxonomy
}

\author{
Eric O'Flynn ${ }^{1}\left[\right.$ D $\cdot$ Arbab Danial $^{2} \cdot$ Jakub Gajewski ${ }^{1}$
}

Received: 9 August 2021 / Accepted: 15 August 2021 / Published online: 25 August 2021

(c) The Author(s) 2021, corrected publication 2022

\begin{abstract}
Global surgery is an emerging field of study and practice, aiming to respond to the worldwide unmet need for surgical care. As a relatively new concept, it is not clear that there is a common understanding of what constitutes "global surgery education and training". This study examines the forms that global surgery education and training programmes and interventions take in practice, and proposes a classification scheme for such activities. A scoping review of published journal articles and internet websites was performed according to the PRISMA Extension for Scoping Review guidelines. PubMed MEDLINE, EMBASE and Google were searched for sources that described global surgery education and training programme. Only sources that explicitly referenced a named education programme, were surgical in nature, were international in nature, were self-described as "global surgery" and presented new information were included. Three hundred twenty-seven records were identified and 67 were ultimately included in the review. "Global surgery education and training" interventions described in the literature most commonly involved both a High-Income Country (HIC) institution and a Low- and Middle-Income Country (LMIC) institution. The literature suggests that significant current effort is directed towards academic global surgery programmes in HIC institutions and HIC surgical trainee placements in LMICs. Four categories and ten subcategories of global surgery education and training were identified. This paper provides a framework from which to study global surgery education and training. A clearer understanding of the forms that such interventions take may allow for more strategic decision making by actors in this field.
\end{abstract}

Keywords Global surgery $\cdot$ Education $\cdot$ Training $\cdot$ LMIC $\cdot$ Partnership

\section{Background}

Five billion people lack access to safe, affordable, timely surgical care and 143 million extra operations per year are required in Low- and Middle- Income Countries (LMICs) to meet current surgical need [1]. Communicable diseases are declining as a percentage of the global burden of disease but conditions which could be treated by surgery are increasing, indeed an estimated $28 \%$ of the global burden of disease is surgical [2]. The term "Global surgery" has recently entered the lexicon. A commonly cited definition of the field states that global surgery "places priority on

Eric O’Flynn

ericoflynn@rcsi.com

1 Institute of Global Surgery, Royal College of Surgeons in Ireland, Dublin, Ireland

2 School of Medicine, Royal College of Surgeons in Ireland, Dublin, Ireland improving health outcomes and achieving health equity for all people worldwide who are affected by surgical conditions or have a need for surgical care" [3]. Another definition notes that in practice, the term is used "often with an explicit focus on LMICs" [4]. There remains, however, a lack of conceptual clarity and understanding. Abraham et al. find that the term 'global surgery' is not well-understood among health professionals. There is no clear consensus on what it means to be a global surgeon" [5].

Global surgery interventions take many different forms [2]. Education and training of surgical practitioners and allied healthcare workers is a key focus of national efforts to expand access to surgical care [6,7]. It is also a key focus of international surgical partnerships. In a systematic review of global surgery partnerships between North American and LMIC institutions, Jedrzejko et al. [8] find that $81 \%$ of partnerships contain a surgical education or training component.

As we look at the nature of global surgery education and training, it is helpful here to distinguish between the 
academic, predominantly classroom-based acquisition of broad subject knowledge - referred to in this study as "education" and the learning-by-doing, predominantly hospitalbased acquisition of knowledge, skills and attitudes intended to lead to specific, concrete results - referred to in this study as "training." The overlapping concepts of education and training are discussed in detail elsewhere [9]. Although "[t]he last ten years have seen the rise of global surgery as an academic pursuit" [10], in global surgery partnerships, clinical training continues to predominate over academic education [11]. Looking specifically at North-South surgical training partnerships Greive-Price et al. found mostly "educational exchanges between HICs and LMICs" which, in general "flowed North to South... typically at the resident level, with most originating from North America and travelling to sub-Saharan Africa" [12].

It is not clear that there is a shared conception of what constitutes, and what does not constitute, education and training in global surgery. Aiming to clarify what global surgery education and training means in practice, we undertook a scoping review of available literature. A scoping review approach was chosen as such reviews "are an ideal tool to determine the scope or coverage of a body of literature on a given topic... Scoping reviews provide a useful alternative to literature reviews when clarification around a concept or theory is required" [13].

From this scoping review, we then look to categorise selfdescribed global surgery education and training programmes and interventions. This review and taxonomy together clarify the scope of such education and training, who is being taught, and how these programmes and interventions are structured. It is hoped that this study will contribute to thoughtful global surgery education programme design.

\section{Methods}

The study protocol was developed following the PRISMA Extension for Scoping Reviews guidelines [14].

\section{Eligibility Criteria}

Only published journal articles and websites in the English language were included. No time limit was placed on the search; however, as the term "global surgery" is a relatively new "emerging terminology" [4], the oldest source returned in the search is from 2010 [15].

\section{Information Sources}

PubMed MEDLINE and EMBASE databases were searched on 13/05/2021. The PubMed MEDLINE search strategy is shown in Table 1. The electronic database search was
Table 1 PubMed MEDLINE search strategy

"global surgery"[Title/Abstract]

AND

(((“'General Surgery/education”[Mesh]) OR

(“Education”[Mesh])) OR (“Global Health/education”[Mesh]))

OR (educat*[Title/Abstract] OR training [Title/Abstract])

AND

((“"global surgery”[Title/Abstract]) AND ((((“"General Surgery/ education”[Mesh]) OR (“Education”[Mesh])) OR (“Global Health/education"'[Mesh])) OR (educat*[Title/Abstract] OR training[Title/Abstract]))) AND ((((partnership[Title/Abstract]) OR ("International Cooperation"'[Mesh])) OR ("Developing Countries"'[Mesh])) OR (low middle income[Title/Abstract] OR Imic[Title/Abstract]))

This search strategy (with appropriate language) was also used for EmBASE

supplemented by an internet search for relevant grey literature performed on 15/06/2021. This involved searching the term "global surgery" on Google and screening all results within the first 10 search engine result pages for education and training interventions, as well as identifying webpages from personal knowledge. At each stage of screening, EO'F and $\mathrm{AD}$ reviewed sources separately. Where reviewers differed, JG adjudicated.

\section{Selection of Sources of Evidence}

Sources were included if:

1. They explicitly and directly reference a named education or training intervention or programme.

2. The subject of the educational programme is surgical practice, education or policy.

3. The educational programme is "global" or "international" in nature - and at least one of the sites is in a low- or middle-income country.

4. The educational programme is described by the authors as a "global surgery" intervention - or any surgical (sub-)specialty variation on this, e.g. "global urology."

5. The source presents new information, not previously or elsewhere published. Opinion, correspondence and systematic and scoping review articles were excluded.

\section{Results}

Three hundred twenty-seven records were identified. Two hundred fifty-nine were excluded and 67 studies included in the review, as shown in Fig. 1. Table 2 illustrates the characteristics of the included sources. No critical appraisal of sources of evidence was undertaken. 
Fig. 1 Flow chart of the literature search and screening process
Identification of studies via databases and registers

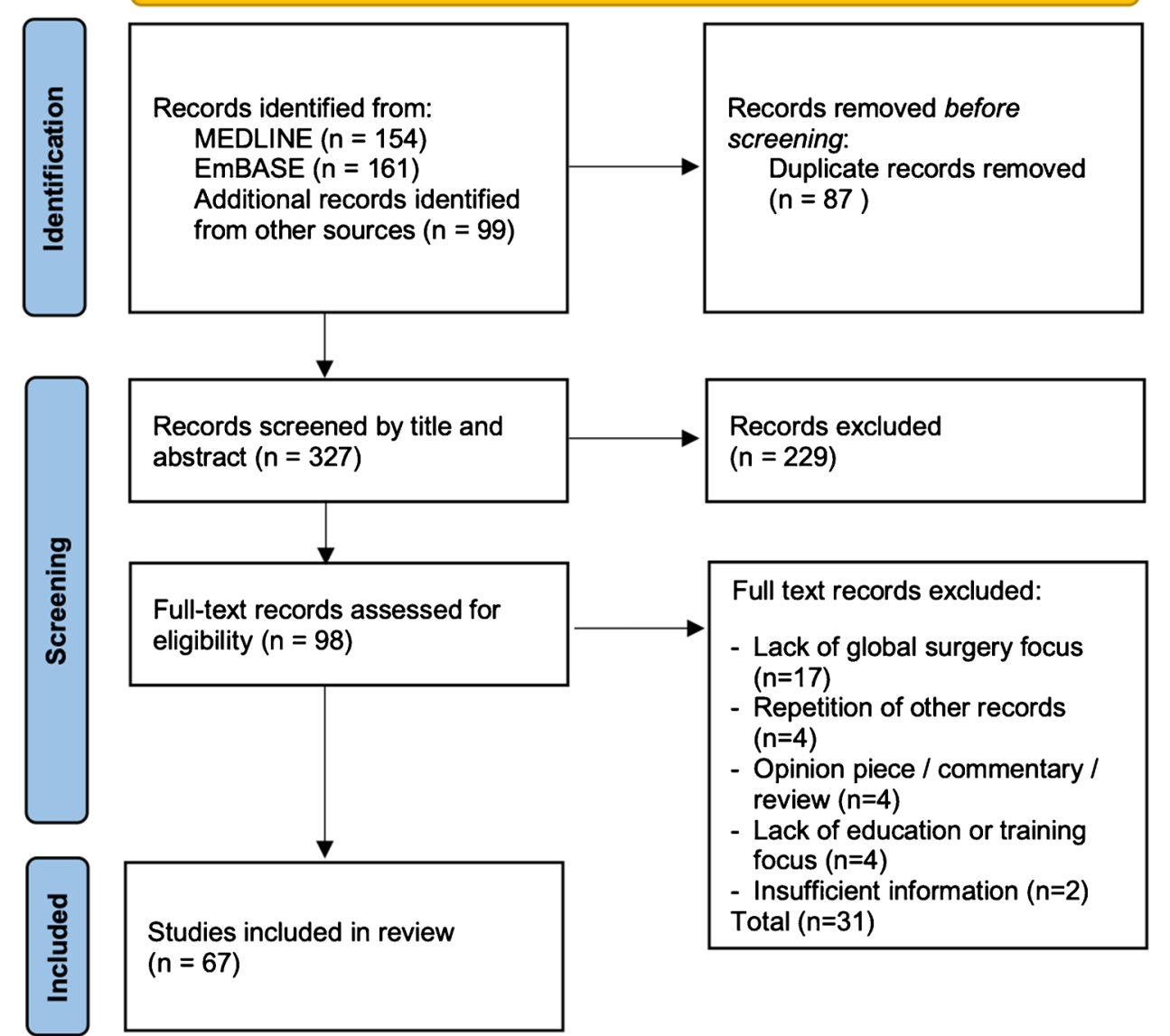

\section{The Meaning of Global Surgery Education and Training in Practice}

This review shows that language of global surgery education and training is used to represent a narrower range of activity than definitions of global surgery aspire to [3, 4]. While de jure global surgery may be considered to be a "worldwide" field of study and practise in some definitions [3], de facto all programmes and interventions included in this review involve interaction between HIC and LMIC institutions, or interaction between HIC institutions and the LMIC surgical care context as the area of study and discussion.

The majority of training interventions found in our review concerned the training of surgeons. One study concerned the training of anaesthetists [16], another the surgical training of medical students [17] and two studies concerned training of different cadres of the surgical team together [18, 19]. Nonspecialist cadres of surgical care provider were trained in two studies [20, 21]. Global surgery education programmes were less explicit in the cadres targeted.

Institutions from the USA were the HIC partner in $67 \%(n=45 / 67)$ of studies. Where a single LMIC partner country was reported, East and Southern African institutions accounted for $63 \%(n=20 / 32)$ of LMIC partners.

\section{Taxonomy of Global Surgery Education and Training Programmes}

Our analysis of programmes which are described using the language of global surgery revealed the existence of four main categories of surgical education and training programmes and ten subcategories as shown in Table 3. Some sources reviewed describe multiple, or multi-faceted, programmes and interventions, and are thus recorded in multiple categories. The categories are as follows:

1. The academic education of surgical care providers, trainees, students, researchers and policy makers on the broad global issues related to the lack of access to safe surgical care [22-46]. A number of HIC universities and training bodies list global surgery education, training and research offerings — which take a wide variety of different forms. Among these are standalone global surgery academic courses, ranging from certificate $[24,26$, 29] to master's degree level [45], and fellowship [34]. 


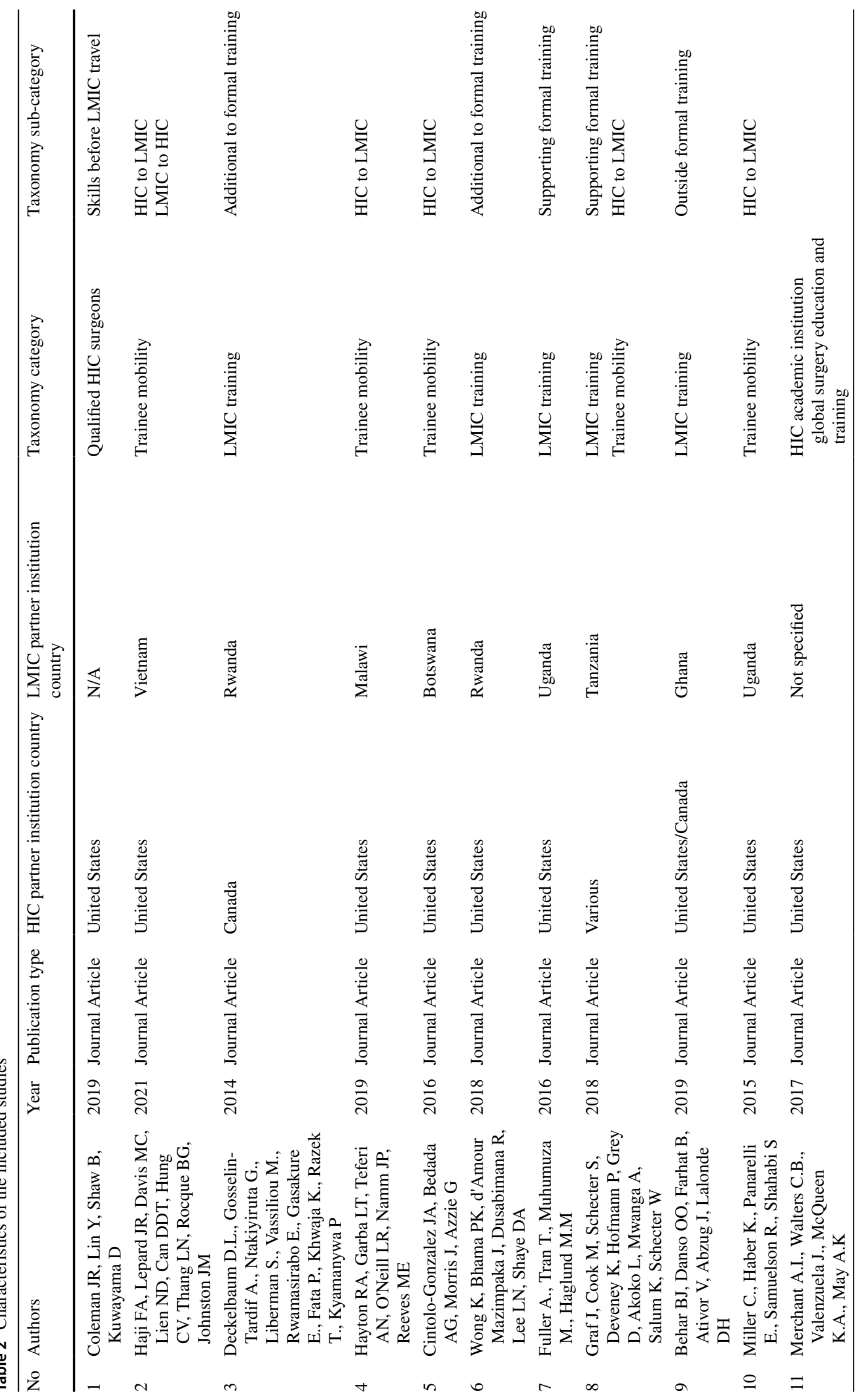




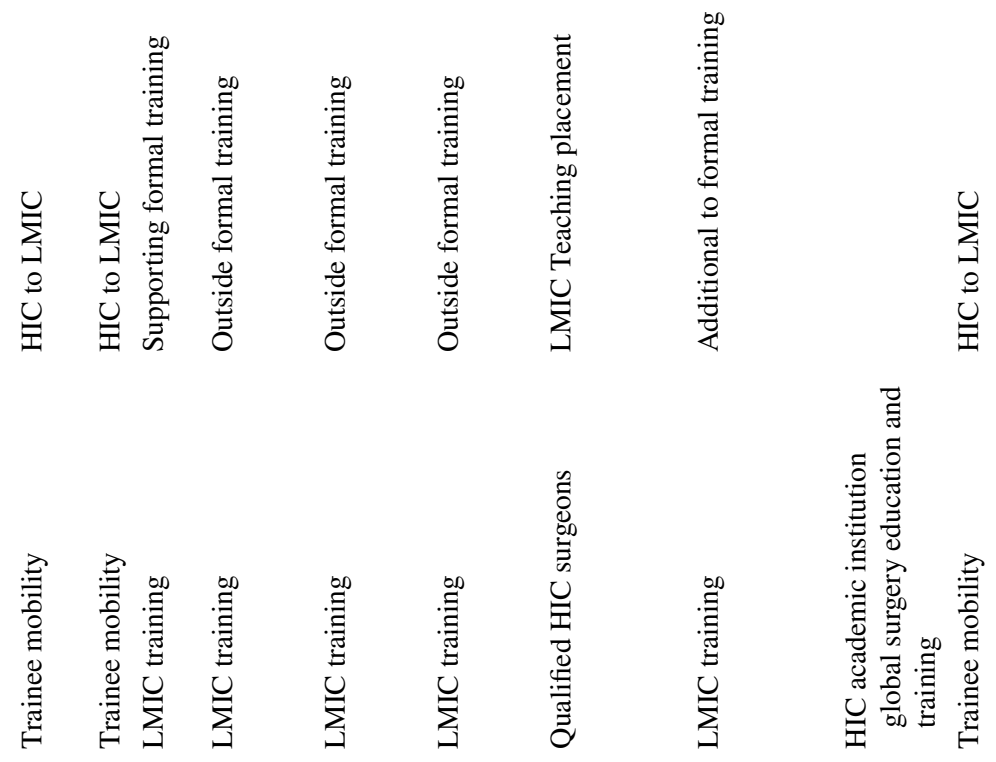

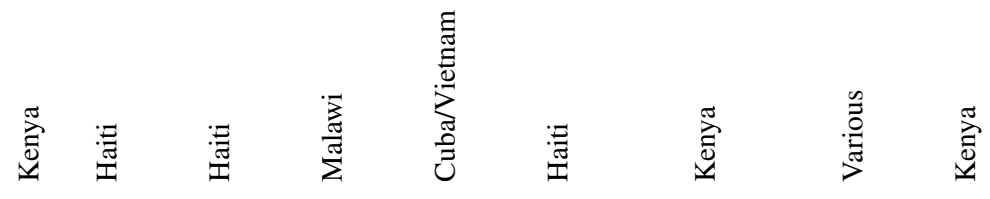

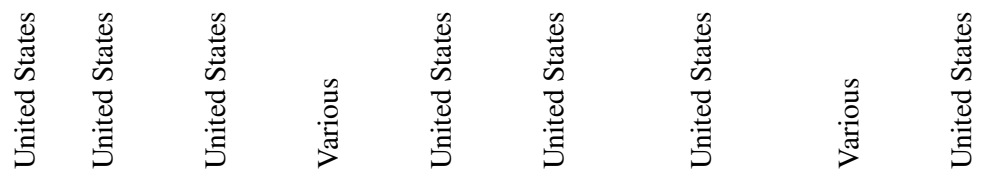

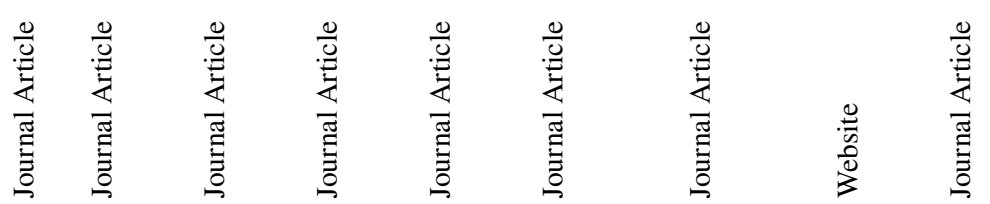

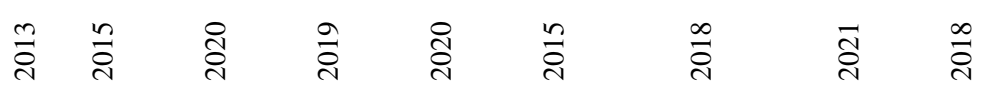

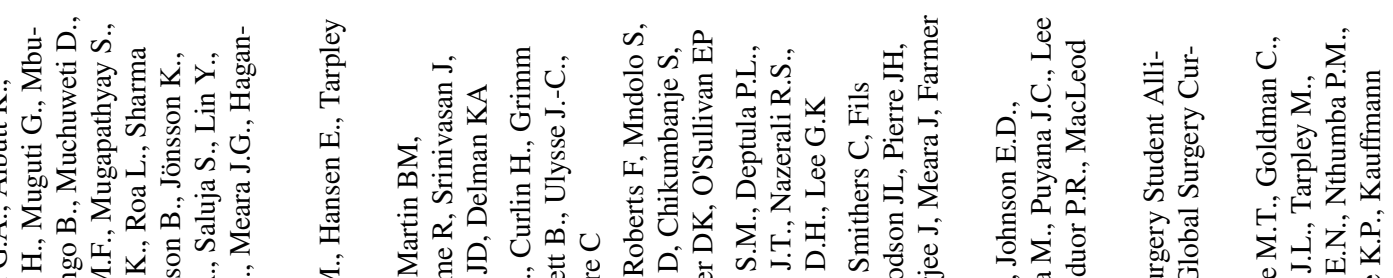




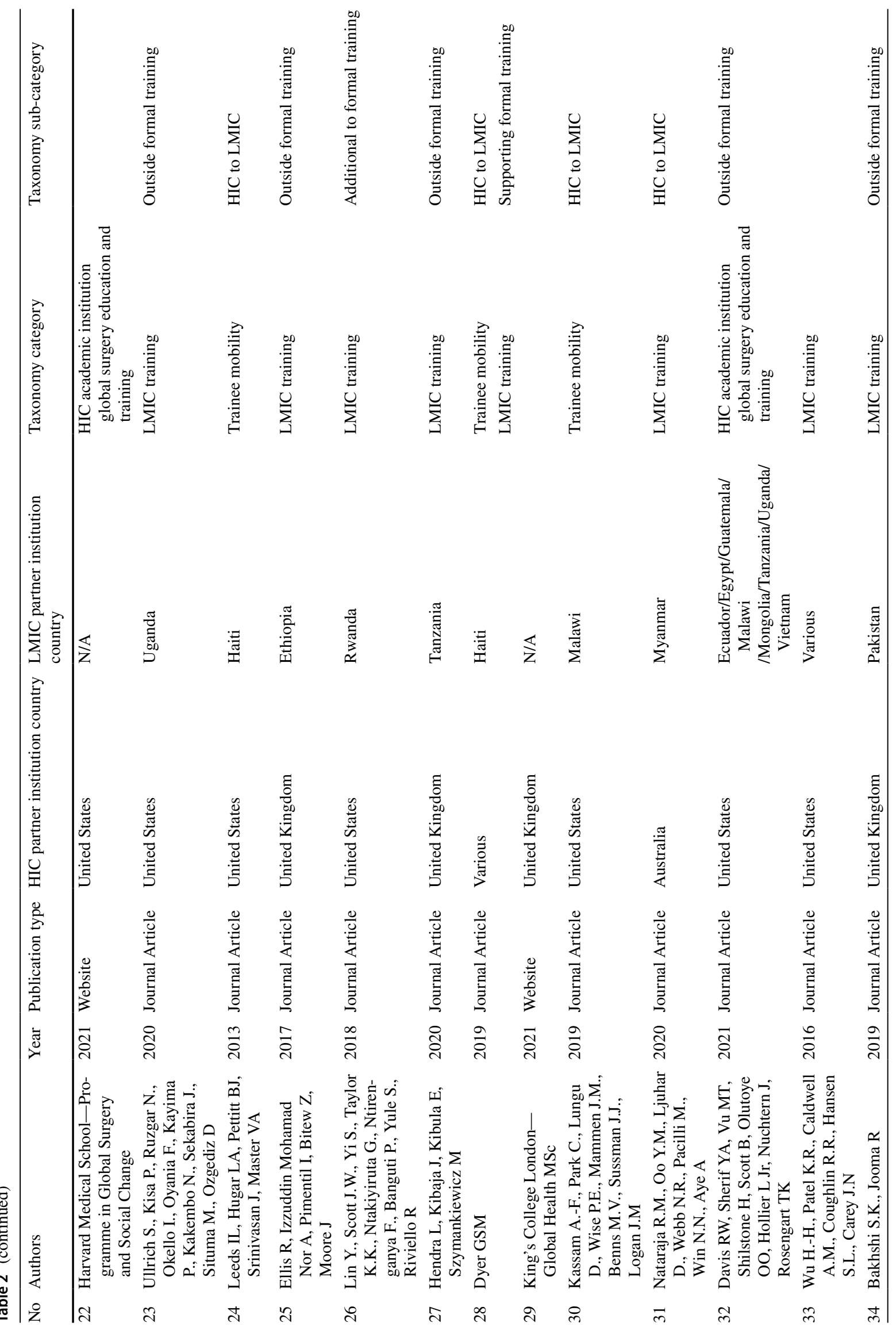




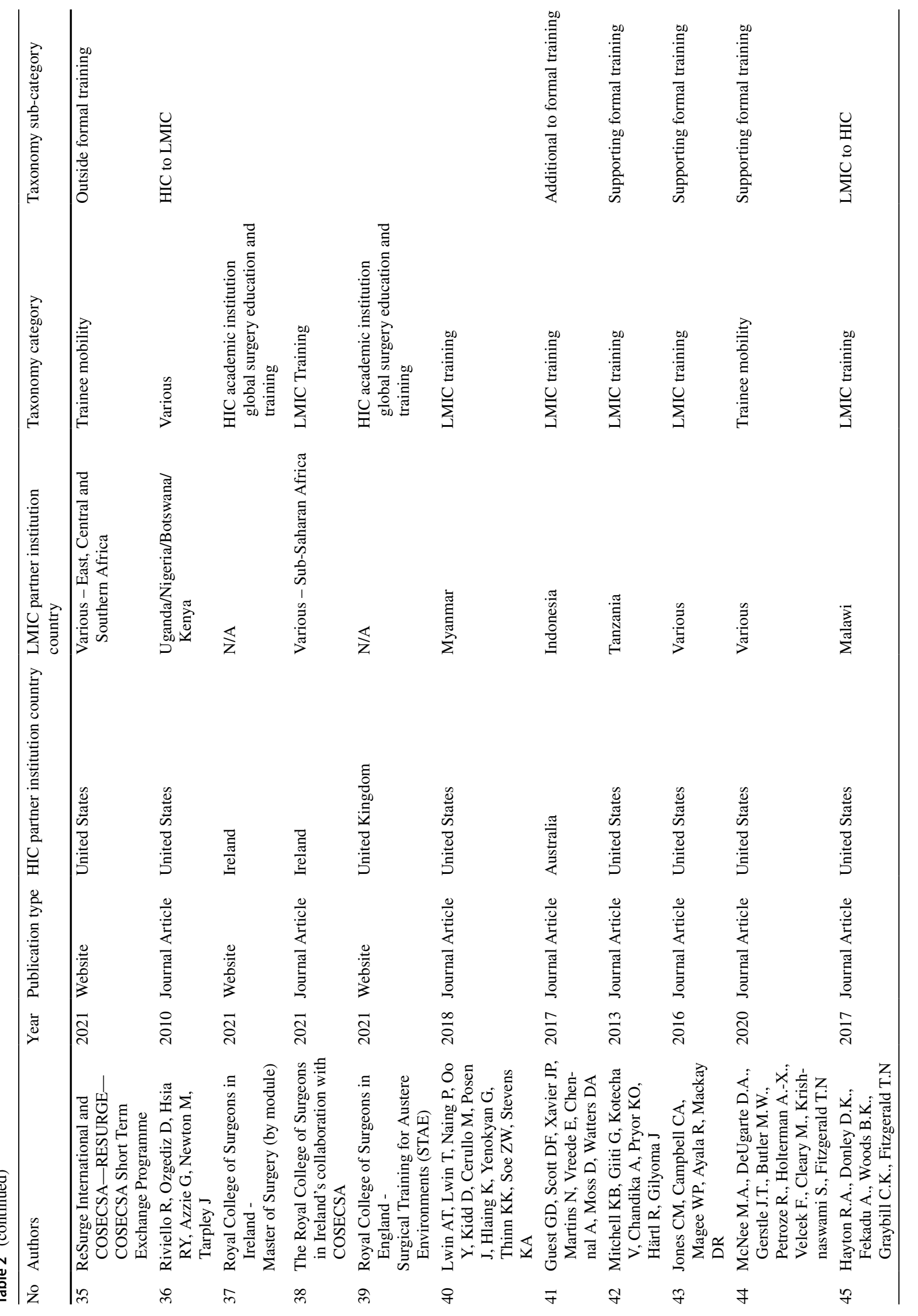




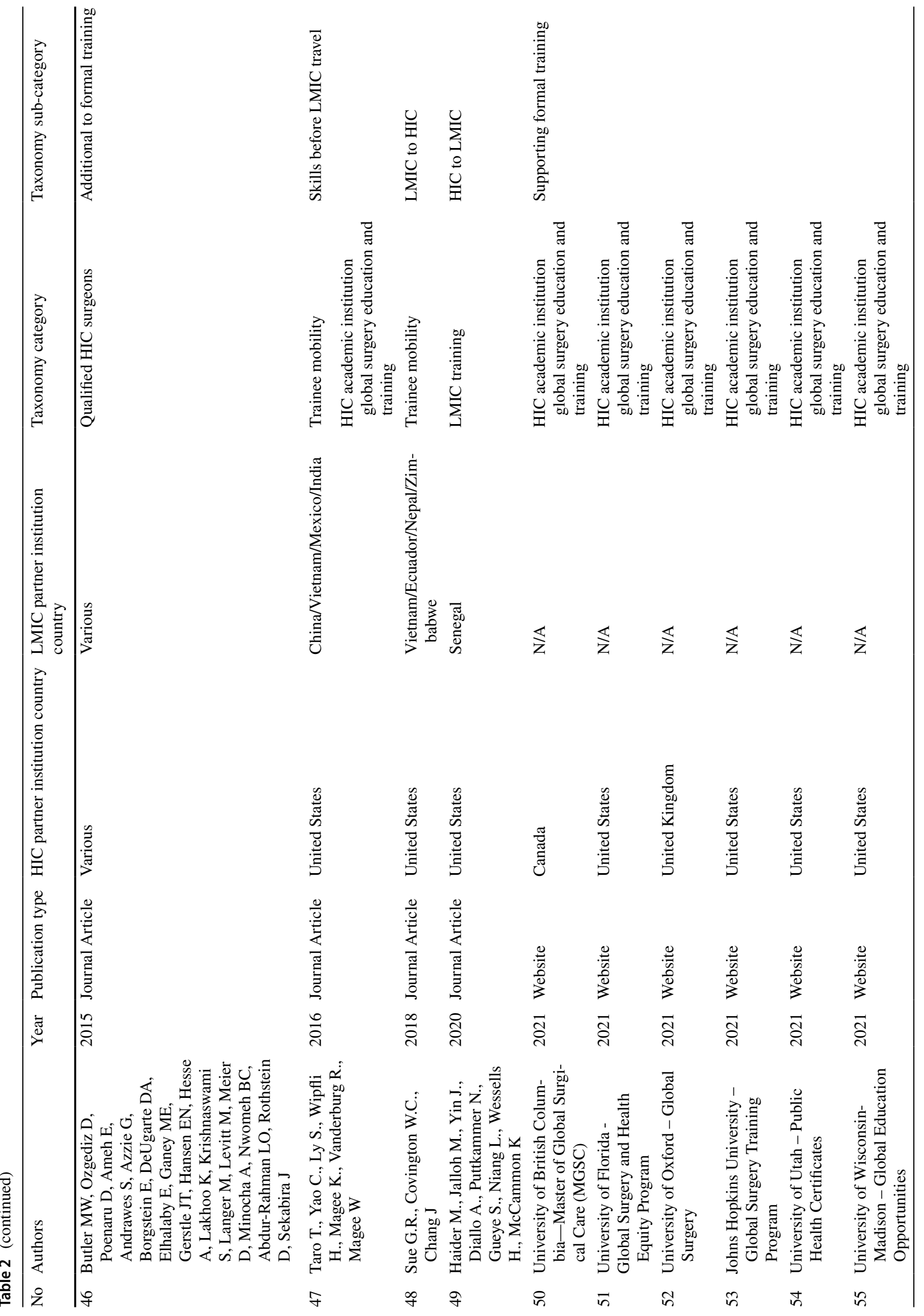




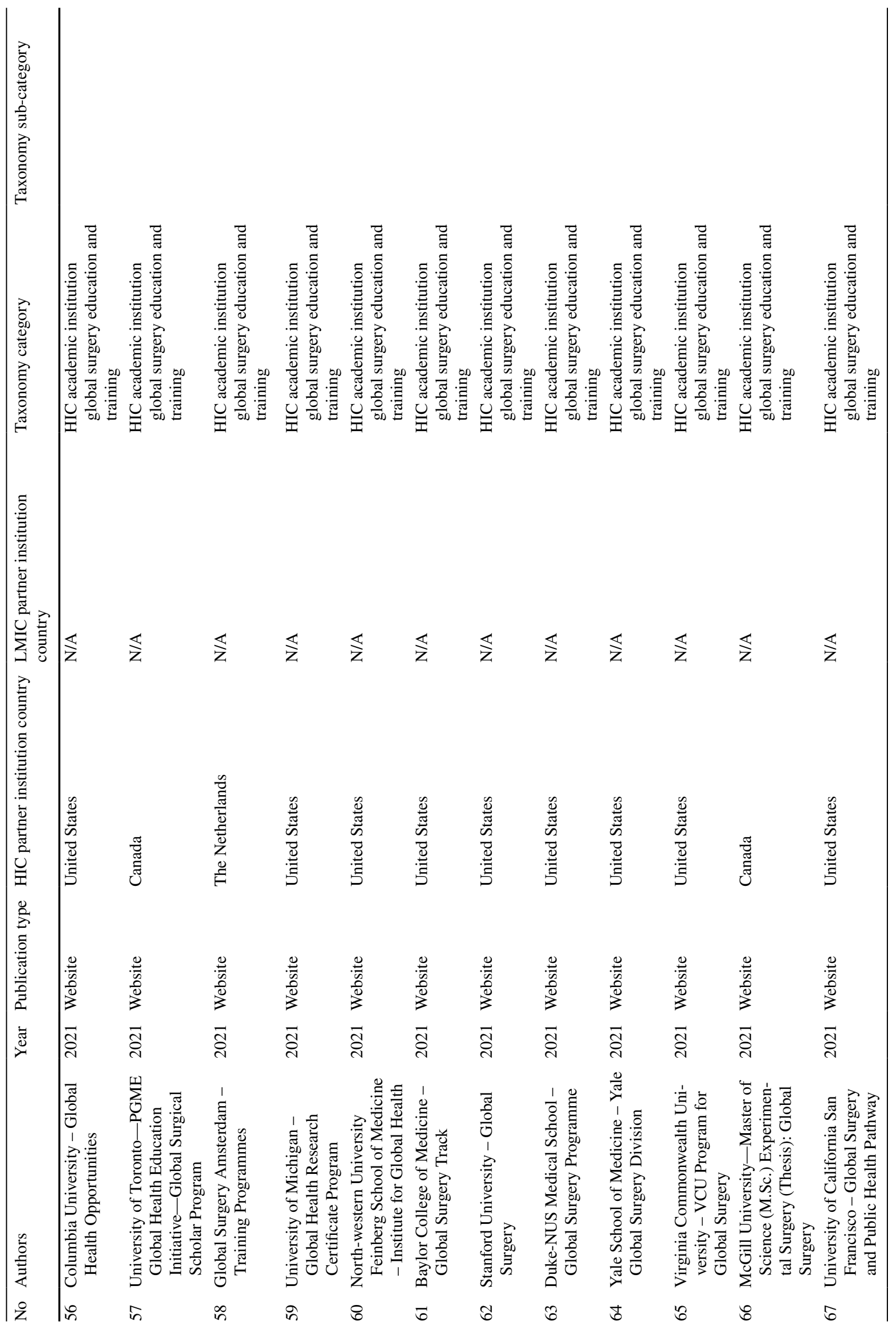


Table 3 Taxonomy of selfdescribed global surgery education and training programmes and interventions

\begin{tabular}{|c|c|c|c|c|}
\hline \multicolumn{2}{|c|}{ Category } & \multicolumn{2}{|c|}{ Sub-category } & \multirow{2}{*}{$\begin{array}{l}\text { Sources } \\
25\end{array}$} \\
\hline 1 & $\begin{array}{l}\text { HIC academic institution global sur- } \\
\text { gery education and training }\end{array}$ & 1 & & \\
\hline \multirow[t]{4}{*}{2} & \multirow[t]{4}{*}{ Trainee mobility } & 2 & HIC to LMIC & 12 \\
\hline & & 3 & LMIC to HIC & 2 \\
\hline & & 4 & Bi-directional & 2 \\
\hline & & 5 & LMIC to LMIC & 1 \\
\hline \multirow[t]{2}{*}{3} & \multirow[t]{2}{*}{ Qualified HIC surgeons } & 6 & LMIC Teaching placement & 7 \\
\hline & & 7 & Skills before LMIC travel & 2 \\
\hline \multirow[t]{3}{*}{4} & \multirow[t]{3}{*}{ LMIC training } & 8 & Supporting formal training & 11 \\
\hline & & 9 & Additional to formal training & 6 \\
\hline & & 10 & Outside formal training & 11 \\
\hline
\end{tabular}

Global surgery education may also form part of other qualifications [40, 42] or be a dedicated track in a surgical training residency [37, 39, 41, 44]. In most cases, these academic programme form part of a surgical training programme, or are targeted at surgical trainees, but in other cases open to "students and trainees" [23], "surgeons, anaesthetists and obstetricians/gynaecologists... those in training including senior medical students... [and] allied health care professions" [24], "graduate students, postgraduate trainees, surgical faculty, or surgeryrelated allied health care workers" [45].

2. The provision of opportunities for surgical practitioners, students and trainees to train and practice abroad. This surgical trainee mobility most commonly involved HIC surgical trainees spending time in LMIC hospitals [47-58]. Less commonly, exchanges involved LMIC surgical trainees travelling to HIC hospitals [43, 59] or bi-directional exchanges $[60,61]$, and in just one case a LMIC-LMIC trainee mobility programme [62].

3. HIC institutional support for surgical training in LMICS - either through support for the delivery an existing formal training programme [15, 53, 56, 58, 63-68], or additional training delivered to trainees enrolled in a formal training programme [17, 18, 48, 69-71], or delivered outside of a formal training programme [16, 19-21, 61, 72-77].

4. Provision of qualified HIC surgical care providers as trainers in LMICs $[15,61,78]$, or the training of such HIC providers to work successfully in low resource environments [79, 80].

\section{Discussion}

\section{Global Surgery Education and Training - a Collaborative Endeavour}

All programmes and interventions included in this review involve both HIC institutions and LMIC institutions or contexts as we have described. Acknowledging that our search strategy and eligibility criteria is likely to have favoured studies that described programmes and interventions undertaken in international partnerships, nevertheless, our review of the literature suggests that surgical training and education programmes, in both HICs and LMICs, are not commonly termed as "global surgery" programmes unless they involve both HIC institutions and LMIC institutions or contexts.

\section{Global Surgery Education in HIC Academic Institutions}

All global surgery academic education programmes identified were in HICs, aimed primarily, but not exclusively, at surgical trainees. It seems likely that these programmes are to some degree a result of HIC student and trainee demand. Patel et al. note that demand for "increased global surgery training reflects the enthusiasm by the current generation of HIC surgical trainees" [81]. This may be expected to benefit the well-intentioned HIC trainee; we support Patel et al.'s assertion that "Training is incomplete for any HIC surgical trainee ... [who does not] have knowledge of the 
global context of surgical care and burden of disease." It also seems plausible that these trainees will have a positive impact in lower resource settings than that in which they trained.

However, if we consider "knowledge of the global context of surgical care and burden of disease" [81] to be of value to LMIC students and trainees, as well as their HIC counterparts, then we must question whether such academic programmes are accessible to LMIC trainees and students, and whether there is a need or demand for such programmes in LMIC contexts. A comparison with the longer established field of global health academic education may be informative in this regard. Svadzian et al. ask "even if HIC universities made their [global health] degrees more accessible, we should still ask why an African trainee must go to London or Boston to learn [about global health]." The question may be equally pertinent when applied to academic global surgery.

\section{Surgical Trainee Mobility — a Two-Way Street?}

Our review identified many more programmes sending HIC surgical trainees to LMICs, than bi-directional, LMIC to HIC or LMIC to LMIC programmes. This is consistent with the findings of other studies [12]. The presence of HIC surgical trainees may undoubtedly in some circumstances provide significant benefit to the LMIC host institution [48, 82]. However this apparent lack of reciprocity in travel, as similarly identified elsewhere [83], may also give us cause for concern. It is incumbent upon us as practitioners in a field dedicated to "achieving health equity for all people worldwide who are affected by surgical conditions" [3], to consider how much satisfying HIC demand for LMIC surgical placements should be a priority for the global surgical community.

\section{Expanding the Focus of Global Surgery Education and Training in the Literature}

Global surgery may be conceived of as involving "surgeons, anaesthetists, nurses and allied healthcare professionals working together with non-clinicians, including policy makers, epidemiologists and economists" [4] but this multidisciplinarity is not currently reflected in the global surgery education and training literature. Similarly, the predominance of the USA and East and Southern Africa in the literature does not seem to reflect the global nature that the field aspires to.

\section{COVID 19 - an Opportunity for a Rethink}

We believe the greatest surgical return on educational investment is in low-resource settings, and thus support for local training programme is likely to be highly impactful. Surgeons trained locally, stay locally [84]. Many of the models of international cooperation described in this study rely heavily on travel, which has been dramatically curtailed due to the pandemic. While hugely disruptive, this may also be "an opportunity to rethink global cooperation in higher education and research" [85]. Innovative approaches to the delivery of global surgery education and training at a distance may prove more efficient than models based on trainees and surgeons flying across the world [86]. Notable in this regard is the launch of the US\$5million Global Surgical Training Challenge Prize [87], which represents a new approach to supporting LMIC surgical training innovation, leveraging expertise across the world, without any in-person meeting.

\section{South-South Cooperation}

Trainee rotations in other low-resource environments may offer more contextually appropriate learning opportunities than rotations in high-resource environments. HIC institutions can facilitate such rotations as ReSurge is doing for plastic surgery trainees of the College of Surgeons of East, Central and Southern Africa (COSECSA) [62]. Similarly, local LMIC developed training content may be more appropriate than content developed elsewhere. HIC institutions may play a useful role here also in facilitating the creation of such resources such as the pan-African paediatric surgery e-learning platform developed by the West African College of Surgeons and COSECSA, facilitated by RCSI and KidsOR [88].

\section{Limitations}

As the study aims to understand what it is meant by global surgery education and training through analysis of programmes using that language, it necessarily does not include studies which may be conceived of as global surgical in nature, yet which do not use the term. As an "emerging terminology" [4], the use of the term "global surgery" in relation to education and training is still evolving.

The search returned little information about programmes related to the education and training of anaesthetists, nurses, non-specialist surgical providers and allied professionals. Use of terms referring to other members of the surgical team such as "global anaesthesia" - may produce different results.

The taxonomy produced is by necessity reductive, many global surgery education programmes may recognise their work in a number of these conceptions. Many programmes which enable HIC country trainees to spend time in Lowand Middle-Income Countries (LMICs) also provide training for such HIC trainees pre-departure, and provide reciprocal opportunities for LMIC trainees to spend time in a highresource environment. The authors' own institution supports formal surgical and anaesthesiology training programmes 
in LMICs [89], supports in-service training and capacity development outside of formal training programmes [90], and delivers academic and clinical global surgery education to students and trainees in Ireland.

\section{Conclusion}

The growth of the global surgery paradigm presents an opportunity to leverage international cooperation to expand and enhance education and training programmes which ultimately benefit the surgical patient, worldwide. This paper provides a framework from which to further study global surgery education and training. Our review suggests that significant effort has been directed towards global surgery programmes in HIC academic institutions and HIC surgical trainee placements in LMICs. The ultimate impact of the identified categories on the surgical patient remains to be determined; however, a clearer understanding of the forms that global surgery education and training interventions take may allow for more strategic decision making by all partners.

Author Contribution EOF conceived study design, with input from JG. $\mathrm{AD}$ and EOF conducted initial reviews at each stage, and JG adjudicated. EOF, AD and JG interpreted the results and wrote the manuscript.

Funding Open Access funding provided by the IReL Consortium.

Data Availability Data analysed during this study are listed in the article.

Code Availability Not applicable.

\section{Declarations}

Conflict of Interest The authors declare no competing interests.

Open Access This article is licensed under a Creative Commons Attribution 4.0 International License, which permits use, sharing, adaptation, distribution and reproduction in any medium or format, as long as you give appropriate credit to the original author(s) and the source, provide a link to the Creative Commons licence, and indicate if changes were made. The images or other third party material in this article are included in the article's Creative Commons licence, unless indicated otherwise in a credit line to the material. If material is not included in the article's Creative Commons licence and your intended use is not permitted by statutory regulation or exceeds the permitted use, you will need to obtain permission directly from the copyright holder. To view a copy of this licence, visit http://creativecommons.org/licenses/by/4.0/.

\section{References}

1. Meara JG, Leather AJM, Hagander L et al (2015) Global Surgery 2030: evidence and solutions for achieving health, welfare, and economic development. Lancet 386:569-624. https://doi.org/10. 1016/S0140-6736(15)60160-X
2. Shrime MG, Sleemi A, Ravilla TD (2015) Charitable platforms in global surgery: a systematic review of their effectiveness, cost-effectiveness, sustainability, and role training. World J Surg 39:10-20. https://doi.org/10.1007/s00268-014-2516-0

3. Dare AJ, Grimes CE, Gillies R et al (2014) Global surgery: defining an emerging global health field. Lancet 384:2245-2247. https://doi.org/10.1016/S0140-6736(14)60237-3

4. Bath M, Bashford T, Fitzgerald JE (2019) What is 'global surgery'? Defining the multidisciplinary interface between surgery, anaesthesia and public health. BMJ Glob Heal 4:e001808. https:// doi.org/10.1136/bmjgh-2019-001808

5. Abraham MN, Abraham PJ, Chen H, Hendershot KM (2020) What is global surgery? Identifying misconceptions among health professionals. Am J Surg 220:271-273. https://doi.org/10.1016/j. amjsurg.2019.11.021

6. Burssa D, Teshome A, Iverson $\mathrm{K}$ et al (2017) Safe surgery for all: early lessons from implementing a National Government-Driven Surgical Plan in Ethiopia. World J Surg 41:3038-3045. https:// doi.org/10.1007/s00268-017-4271-5

7. Truché P, Shoman H, Reddy CL et al (2020) Globalization of national surgical, obstetric and anesthesia plans: the critical link between health policy and action in global surgery. Global Health 16:1-8. https://doi.org/10.1186/s12992-019-0531-5

8. Jedrzejko N, Margolick J, Nguyen JH et al (2021) A systematic review of global surgery partnerships and a proposed framework for sustainability. Can J Surg 64:E280-E288. https://doi.org/10. 1503/cjs.010719

9. Masadeh M (2012) Training, education, development and learning: what is the difference? Eur Sci J 8:62-68

10. Martin AN, Petroze RT (2020) Academic global surgery and COVID19: turning impediments into opportunities. Am J Surg 220:53-54

11. Park J, Cheoun M-L, Choi S et al (2021) The landscape of academic global surgery: a rapid review. J Public Heal Emerg 5(9):9. https://doi.org/10.21037/jphe-20-80

12. Greive-Price T, Mistry H, Baird R (2020) North-South surgical training partnerships: a systematic review. Can J Surg 63:E551E561. https://doi.org/10.1503/cjs.008219

13. Munn Z, Peters MDJ, Stern C et al (2018) Systematic review or scoping review? Guidance for authors when choosing between a systematic or scoping review approach. BMC Med Res Methodol 18:143. https://doi.org/10.1186/s12874-018-0611-x

14. Tricco AC, Lillie E, Zarin W et al (2018) PRISMA Extension for Scoping Reviews (PRISMA-ScR): checklist and explanation. Ann Intern Med 169:467-473. https://doi.org/10.7326/M18-0850

15. Riviello R, Ozgediz D, Hsia RY et al (2010) Role of collaborative academic partnerships in surgical training, education, and provision. World J Surg 34:459-465. https://doi.org/10.1007/ s00268-009-0360-4

16 Jooste R, Roberts F, Mndolo S et al (2019) Global Capnography Project (GCAP): implementation of capnography in Malawi - an international anaesthesia quality improvement project. Anaesthesia 74:158-166. https://doi.org/10.1111/anae.14426

17. Hill KA, Johnson ED, Lutomia M et al (2018) Implementing the Trauma Evaluation and Management (TEAM) course in Kenya. J Surg Res 232:107-112. https://doi.org/10.1016/j.jss.2018.05.066

18. Lin Y, Scott JW, Yi S et al (2018) Improving surgical safety and nontechnical skills in variable-resource contexts: a novel educational curriculum. J Surg Educ 75:1014-1021

19. Ellis R, Izzuddin Mohamad Nor A, Pimentil I et al (2017) Improving surgical and anaesthesia practice: review of the use of the WHO Safe Surgery Checklist in Felege Hiwot Referral Hospital, Ethiopia. BMJ Qual Improv Rep 6:u207104.w6251. https://doi. org/10.1136/bmjquality.u207104.w6251

20. Bakhshi SK, Jooma R (2019) Primary trauma care: a training course for healthcare providers in developing countries. J Pak Med Assoc 69(1):S82-S85 
21. Hendra L, Kibaja J, Kibula E, Szymankiewicz M (2020) Muheza approach: a sustainable mesh hernia service in a resource-poor setting and developing a national methodology to hernia surgery in Tanzania. ANZ J Surg 90:1933-1937. https://doi.org/10.1111/ ans. 16133

22. Merchant AI, Walters CB, Valenzuela J et al (2017) Creating a global acute care surgery fellowship to meet international need. J Surg Educ 74:780-786

23. Global Surgery Student Alliance (2021) Global Surgery Curriculum. https://www.globalsurgerystudents.org/education-series. Accessed 10 Jul 2021

24. University of Oxford (2021) Global Surgery. https://www.conted. ox.ac.uk/courses/global-surgery. Accessed 10 Jul 2021

25. Johns Hopkins University (2021) Global Surgery Training Program. https://www.hopkinsmedicine.org/surgery/education/resid ency/general-surgery/. Accessed 10 Jul 2021

26. University of Utah School of Medicine Center for Global Surgery (2021) Public Health - Certificates. https://medicine.utah. edu/dfpm/public-health/programs/certificates/global-health/cours es.php. Accessed $10 \mathrm{Jul} 2021$

27. University of Wisconsin-Madison (2021) Global education opportunities. https://www.surgery.wisc.edu/global-surgery/globaleducation-opportunities/. Accessed 10 Jul 2021

28. Columbia University (2021) Global Health Opportunities. https:// www.vagelos.columbia.edu/education/academicprograms/mdprogram/curriculum/md-curriculum/differentiation-and-integ ration-d-i/global-health-opportunities. Accessed $10 \mathrm{Jul} 2021$

29. University of Toronto (2021) PGME Global Health Education Initiative - Global Surgical Scholar Program. https://surgery.utoro nto.ca/node/1258. Accessed 10 Jul 2021

30. Global Surgery Amsterdam (2021) Training programmes. https:// globalsurgeryamsterdam.com/education-training/trainingpr ograms. Accessed 10 Jul 2021

31. University of Michigan (2021) Global Health Research Certificate Program. https://medicine.umich.edu/dept/globalreach/globalhealth-research-certificate-program. Accessed 10 Jul 2021

32. Northwestern University Feinberg School of Medicine Institute for Global Health (2021) Center for global surgery. https://www.globa lhealth.northwestern.edu/centers/surgery/index.html. Accessed 10 Jul 2021

33. Stanford University (2021) Global Surgery. https://surgery.stanf ord.edu/about/global-surgery.html. Accessed 10 Jul 2021

34. Harvard Programme in Global Surgery and Social Change (2021) Harvard Programme in Global Surgery and Social Change. https:// www.pgssc.org/national-surgical-planning. Accessed 10 Jul 2021

35. Duke-NUS Medical School (2021) Global surgery programme. https://www.singhealthdukenus.com.sg/acp/surgery/globalsurg ery-programme. Accessed 10 Jul 2021

36. Yale School of Medicine (2021) Yale global surgery division. https://medicine.yale.edu/surgery/education/global/. Accessed 10 Jul 2021

37. Virginia Commonwealth University (2021) VCU Program for global surgery. https://surgery.vcu.edu/research/globalsurgery/. Accessed 10 Jul 2021

38. McGill University (2021) Master of Science (M.Sc.) Experimental Surgery (Thesis): Global Surgery. https://www.mcgill.ca/study/ 2021-2022/faculties/medicine/graduate/programs/master-sciencemsc-experimental-surgery-thesis-global-surgery. Accessed $10 \mathrm{Jul}$ 2021

39. University of California San Francisco (2021) Global Surgery and Public Health Pathway. https://surgeryresidentresearch.ucsf. edu/research-pathways/research-pathways/global-surgery-publichealth.aspx. Accessed 10 Jul 2021

40. King's College London (2021) Global Health MSc. https://www. kcl.ac.uk/study/postgraduate/taught-courses/global-health-msc. Accessed 10 Jul 2021
41. Davis RW, Sherif YA, Vu MT et al (2021) Personalized graduate medical education and the global surgeon: training for resourcelimited settings. Acad Med 96:384-389. https://doi.org/10.1097/ ACM.0000000000003898

42. Royal College of Surgeons in Ireland (2021) Master of Surgery (by module). https://www.rcsi.com/dublin/postgraduate/taught-cours es/master-of-surgery-by-module-pt/course-details. Accessed 10 Jul 2021

43. Taro T, Yao C, Ly S et al (2016) The global surgery partnership: an innovative partnership for education, research, and service. Acad Med 91:75-78

44. Baylor College of Medicine (2021) Global Surgery Track. https:// www.bcm.edu/departments/surgery/education/training-programs/ general-surgery-residency/global-surgery-track. Accessed $10 \mathrm{Jul}$ 2021

45. The University of British Columbia (2021) Master of Global Surgical Care(MGSC). https://www.grad.ubc.ca/prospectivestudents/graduate-degree-programs/master-global-surgical-care. Accessed 10 Jul 2021

46. University of Florida (2021) Global Surgery and Health Equity Program. https://surgery.med.ufl.edu/education/global-surgery/. Accessed 10 Jul 2021

47. Tarpley M, Hansen E, Tarpley JL (2013) Early experience in establishing and evaluating an ACGME-approved international general surgery rotation. J Surg Educ 70:709-714. https://doi.org/ 10.1016/j.jsurg.2013.04.016

48. Hayton RA, Donley DK, Fekadu A et al (2017) Surgical volunteerism as a collaborative teaching activity can benefit surgical residents in low-middle income countries. Int J Surg 48:34-37. https://doi.org/10.1016/j.ijsu.2017.08.589

49. Kassam A-F, Park C, Lungu D et al (2019) Multi-Institutional Approach to Establishing a Sustainable Academic Global Surgery Program. J Am Coll Surg 229:S134-S135

50. Sue GR, Covington WC, Chang J (2018) The ReSurge Global Training Program: a model for surgical training and capacity building in global reconstructive surgery. Ann Plast Surg 81:250-256

51. LeCompte MT, Goldman C, Tarpley JL et al (2018) Incorporation of a global surgery rotation into an academic general surgery residency program: impact and perceptions. World J Surg 42:2715-2724

52. Cintolo-Gonzalez JA, Bedada AG, Morris J, Azzie G (2016) An international surgical rotation as a systems-based elective: the Botswana-University of Pennsylvania surgical experience. J Surg Educ 73:355-359. https://doi.org/10.1016/j.jsurg.2015.09.019

53. Graf J, Cook M, Schecter S et al (2018) Coalition for global clinical surgical education: the alliance for global clinical training. J Surg Educ 75:688-696. https://doi.org/10.1016/j.jsurg.2017.08. 019

54. Miller C, Haber K, Panarelli E et al (2015) Collaborative resident education at a large teaching hospital in Kampala, Uganda. Ann Glob Heal 81:41-42

55. Anderson GA, Albutt K, Holmer H et al (2019) Development of a Novel Global Surgery Course for Medical Schools. J Surg Educ 76:469-479

56. Love TP, Martin BM, Tubasiime R et al (2015) Emory global surgery program: learning to serve the underserved well. J Surg Educ 72:e46-51. https://doi.org/10.1016/j.jsurg.2015.01.006

57. Leeds IL, Hugar LA, Pettitt BJ et al (2013) International surgical clerkship rotation: perceptions and academic performance. Am J Surg 206:280-286. https://doi.org/10.1016/j.amjsurg.2012.10.034

58. Dyer GSM (2019) International Partnerships for Hand Surgery Education. Hand Clin 35:435-440. https://doi.org/10.1016/j.hcl. 2019.07.007 
59. McNee MA, DeUgarte DA, Gerstle JT et al (2021) The first six years of the APSA travel fellowship program: impact and lessons learned. J Pediatr Surg 56:862-867

60. Haji FA, Lepard JR, Davis MC et al (2021) A model for global surgical training and capacity development: the Children's of Alabama-Viet Nam pediatric neurosurgery partnership. Child's Nerv Syst 37:627-636. https://doi.org/10.1007/s00381-020-04802-4

61. Butler MW, Ozgediz D, Poenaru D et al (2015) The Global Paediatric Surgery Network: a model of subspecialty collaboration within global surgery. World J Surg 39:335-342

62. ReSurge International and COSECSA (2021) RESURGE COSECSA Short Term Exchange Programme. http://www. cosecsa.org/resurge-cosecsa-short-term-exchange-programme/. Accessed $10 \mathrm{Jul} 2021$

63. Haider M, Jalloh M, Yin J et al (2020) The role of international partnerships in improving urethral reconstruction in low- and middle-income countries. World J Urol 38:3003-3011

64. Guest GD, Scott DF, Xavier JP et al (2017) Surgical capacity building in Timor-Leste: a review of the first 15 years of the Royal Australasian College of Surgeons-led Australian Aid programme. ANZ J Surg 87:436-440. https://doi.org/10.1111/ans.13768

65. Mitchell KB, Giiti G, Kotecha V et al (2013) Surgical education at Weill Bugando Medical Centre: supplementing surgical training and investing in local health care providers. Can J Surg 56:199-203. https://doi.org/10.1503/cjs.028911

66 Fuller A, Tran T, Muhumuza M, Haglund MM (2016) Building neurosurgical capacity in low and middle income countries. eNeurologicalSci 3:1-6

67. Tierney S, O'Flynn E (2014) The Royal College of Surgeons in Ireland's Collaboration with COSECSA. J Assoc Surg Gt Britain Irel 43(42):43

68. Jones CM, Campbell CA, Magee WP et al (2016) The expanding role of education and research in international healthcare. Ann Plast Surg 76(Suppl 3):S150-S154. https://doi.org/10.1097/SAP. 0000000000000721

69. Lwin AT, Lwin T, Naing P et al (2018) Self-directed interactive video-based instruction versus instructor-led teaching for Myanmar house surgeons: a randomized, noninferiority trial. J Surg Educ 75:238-246. https://doi.org/10.1016/j.jsurg.2017.06.004

70. Deckelbaum DL, Gosselin-Tardif A, Ntakiyiruta G et al (2014) An innovative paradigm for surgical education programs in resourcelimited settings. Can J Surg 57:298-299

71. Wong K, Bhama PK, d'Amour Mazimpaka J et al (2018) Banana fruit: an "appealing" alternative for practicing suture techniques in resource-limited settings. Am J Otolaryngol 39:582-584. https:// doi.org/10.1016/j.amjoto.2018.06.021

72. Wu H-H, Patel KR, Caldwell AM et al (2016) Surgical management and reconstruction training (SMART) course for orthopaedic surgeons: a 1-year prospective analysis. Lancet Glob Heal 4:11

73. Behar BJ, Danso OO, Farhat B et al (2019) Collaboration in outreach: the Kumasi, Ghana. Model Hand Clin 35:429-434. https:// doi.org/10.1016/j.hcl.2019.07.009

74. Harvey L, Curlin H, Grimm B et al (2020) Experience with a novel laparoscopic gynecologic curriculum in Haiti: lessons in implementation. Surg Endosc 34:2035-2039

75. Inchauste SM, Deptula PL, Zelones JT et al (2020) Global health microsurgery training with cell phones. Ann Plast Surg 84:S273-S277
76. Ullrich S, Kisa P, Ruzgar N et al (2021) Implementation of a contextually appropriate pediatric emergency surgical care course in Uganda. J Pediatr Surg 56:811-815

77. Nataraja RM, Oo YM, Ljuhar D et al (2020) Overview of a novel paediatric surgical simulation-based medical education programme in Myanmar. ANZ J Surg 90:1925-1932

78. Aarabi S, Smithers C, Fils M-ML et al (2015) Global Surgery Fellowship: a model for surgical care and education in resource-poor countries. J Pediatr Surg 50:1772-1775. https://doi.org/10.1016/j. jpedsurg.2015.06.009

79. Royal College of Surgeons of England (2021) Surgical Training for Austere Environments (STAE). https://www.rcseng.ac.uk/ education-and-exams/courses/search/surgical-training-for-auste re-environments-stae/. Accessed 10 Jul 2021

80. Coleman JR, Lin Y, Shaw B, Kuwayama D (2019) A cadaverbased course for humanitarian surgery improves manual skill in powerless external fixation. J Surg Res 242:270-275. https://doi. org/10.1016/j.jss.2019.04.061

81. Patel R, Khundkar R, Peter N et al (2019) Improving global surgery education for trainees. IJS Glob Health 2:7

82. Hayton RA, Garba LT, Teferi AN et al (2019) An international mutually beneficial global surgery rotation in Malawi. J Grad Med Educ 11:193-194. https://doi.org/10.4300/JGME-D-18-01021

83. Grant CL, Robinson T, Al Hinai A et al (2020) Ethical considerations in global surgery: a scoping review. BMJ Glob Heal 5:e002319. https://doi.org/10.1136/bmjgh-2020-002319

84. Hutch A, Bekele A, O'Flynn E et al (2017) The brain drain myth: retention of specialist surgical graduates in East, Central and Southern Africa, 1974-2013. World J Surg 41:3046-3053. https:// doi.org/10.1007/s00268-017-4307-x

85. Buitendijk S, Ward H, Shimshon G et al (2020) COVID-19: an opportunity to rethink global cooperation in higher education and research. BMJ Glob Heal 5:e002790. https://doi.org/10.1136/ bmjgh-2020-002790

86. Agrawal V, Sharma D (2020) Surgical training "Before COVID-19 (BC)" to "After COVID-19 (AC)": needs-driven approach for the Global South. BJS (British J Surgery) 107:e585-e586. https://doi. org/10.1002/bjs. 12022

87. Global Surgical Training Challenge (2021) Global Surgical Training Challenge. https://globalsurgicaltraining.challenges.org/. Accessed 10 Jun 2021

88. Royal College of Surgeons in Ireland African Paediatric Surgery E-learning (2021) https://www.rcsi.com/surgery/globalsurgery/ our-work/african-paediatric-surgery-elearning. Accessed $10 \mathrm{Jul}$ 2021

89. O’Flynn E, Erzingatsian K, Magee D (2019) Operating together: 12 years of collaboration between RCSI and COSECSA. Dublin

90. Gajewski J, Monzer N, Pittalis C et al (2020) Supervision as a tool for building surgical capacity of district hospitals: the case of Zambia. Hum Resour Health 18:25. https://doi.org/10.1186/ s12960-020-00467-x

Publisher's Note Springer Nature remains neutral with regard to jurisdictional claims in published maps and institutional affiliations. 